\title{
Direct Measurement of Surface Complex Loading and Surface Dipole and Their Effect on Simple Device Behavior
}

\author{
Jing Guo ${ }^{\dagger}$ Norbert Koch,, Jeffrey Schwartz, ${ }^{*, \dagger}$ and Steven L. Bernasek ${ }^{\dagger}$ \\ Department of Chemistry, Princeton University, Princeton, New Jersey 08544-1009, and \\ Institut für Physik, Humboldt-Universität zu Berlin, D-12489 Berlin, Germany
}

Received: August 13, 2004; In Final Form: December 15, 2004

\begin{abstract}
Tin complexes of phenoxide ligands having a range of dipole moments were prepared on the surface of indium-tin oxide (ITO). Surface complex loadings and stoichiometries were measured by quartz crystal microgravimetry. Work functions of ITO substrates treated with these various surface complexes were measured using a Kelvin probe. Surface complex dipole moments were then calculated based on measured surface loadings. Changes in the ITO work function effected by surface phenoxide complex introduction correlate with these surface complex dipole moments and with total surface dipole per unit area, and current densities in simple hole-only diode devices also correlate with these total surface dipoles.
\end{abstract}

Surface modification of indium-tin oxide (ITO) has received wide attention as a means to control its anode properties, particularly to increase its work function $(\phi)$ in order to lower the barrier to hole injection in novel organic-based optoelectronic devices. ${ }^{1-7}$ The Helmholtz expression derived from simple electrostatics, $\Delta \phi=q n \Delta \mu_{\perp} / \epsilon_{\mathrm{r}} \epsilon_{0}$, provides the conceptual basis for many practical attempts to enable this change in work function; here, $q$ is the elementary charge, $n$ is the surface dipole density, $\Delta \mu_{\perp}$ is the dipole moment perpendicular to the surface, $\epsilon_{\mathrm{r}}$ is the relative dielectric constant, and $\epsilon_{0}$ is the vacuum permittivity. ${ }^{8}$ An elegant model that has been proposed ${ }^{9}$ within this context is based on an introduced dipole layer on the surface of the ITO: ${ }^{10,11}$ If the negative end of the surface dipole species points away from the ITO surface, the work function of ITO is increased, and the hole injection barrier is decreased. ${ }^{11,12}$ The effected work function change $(\Delta \phi)$ should be directly proportional to the normal component of molecular dipole moments of surface-attached species $\left(\mu_{z}\right)$ and to the number of such species, per unit area, on the surface, $, 9,12$ in conformity to the Helmholtz expression. Many studies using organics to effect work function changes for ITO, for example, by surface deposition of organic acids ${ }^{13-15}$ or surface silanization ${ }^{16}$ with hole transport materials derivatives, have been described qualitatively. However, in the absence of structural or surface loading information for the surface dipolar species, no quantitative relationships between them and measured values for $\Delta \phi$ or their impact on device behavior could be established.

We have described surface modification of ITO in an ultrahigh vacuum (UHV) using a series of tin phenoxides, ${ }^{17}$ and we showed that a correlation existed between dipole moments of the parent phenols and changes in the ITO work function that occurred on formation of the surface complexes. ${ }^{18}$ Yet, even for these well-defined surface species, surface loadings were not known. We have reported that the surface deposition and ligand metathetical reactions for tin alkoxides on ITO recorded in $\mathrm{UHV}^{17,18}$ can be accomplished under normal laboratory

* To whom correspondence should be addressed. E-mail: jschwartz@ princeton.edu.

Princeton University.

$\doteqdot$ Institut für Physik. conditions. ${ }^{17}$ We now demonstrate that performing these deposition and metathesis reactions on an ITO electrode-equipped quartz crystal microbalance (QCM) gives us surface complex loadings which, together with Kelvin probe vibrating capacitor measurements of the ITO work function, enables calculation of surface complex dipole moments to be made and to be related to the "dipole model". In support of the Helmholtz model, we find that there is a good correlation between total surface dipole per unit area and $\Delta \phi$ effected by ligand substitution in surface tin phenoxide complexes. Significantly, we show that these values for $\Delta \phi$ correlate well with current density enhancements measured in simple hole-only diode devices; thus controlled surface modification chemistry and diode device behavior can now be related quantitatively.

\section{Experimental Section}

General. Tetra(tert-butoxy)tin (1) was used as received (Aldrich) and was stored under nitrogen. Phenol (4a) (Allied Chemical), $p$-fluorophenol (4b) (Aldrich), 4-(trifluoromethyl)phenol (4c) (Lancaster), and 2,6-difluorophenol (4d) (Aldrich) were used as received and were stored under nitrogen. Glass slides coated with indium-tin oxide (Colorado Concept Coatings, $15 \Omega / \square, 1500 \AA$ ) were first cut into pieces of approximately 1 $\mathrm{cm}^{2}$. They were cleaned by rinsing with sonication for $30 \mathrm{~min}$ in 2\% aq NP-10 Tergitol solution, rinsing thoroughly with deionized water, rinsing with sonication for $5 \mathrm{~min}$ in acetone, submerging for $5 \mathrm{~min}$ in boiling trichloroethylene (3 cycles), submerging for $5 \mathrm{~min}$ in acetone (3 cycles), and submerging for $5 \mathrm{~min}$ in boiling methanol ( 3 cycles). They were then heated at $100{ }^{\circ} \mathrm{C}$ for $1 \mathrm{~h}$ in vacuo and then stored in a holding chamber under vacuum $\left(10^{-2}\right.$ Torr). Reflectance absorbance IR spectra were taken using a MIDAC FT-IR, with a blank ITO slide as the background.

[ITO]-[O]-Sn $\left(\mathbf{O B u}^{t}\right)_{3}$. ITO samples were placed in a vacuum chamber $\left(10^{-3}\right.$ Torr $)$ and were exposed to vapor of $\mathbf{1}$ for $5 \mathrm{~min}$ under active vacuum. The active vacuum was closed off, and the chamber was cooled externally with dry ice for $10 \mathrm{~min}$ to help with the condensation of $\mathbf{1}$. The chamber was then evacuated at room temperature to remove excess physisorbed 1. 
[ITO]-[O]- $\mathrm{Sn}\left(\mathrm{OBu}^{t}\right)\left(\mathrm{OC}_{6} \mathbf{H}_{5}\right)_{2}$ (5a). Samples of 2 were treated with vapor of $\mathbf{4 a}$ for 5 min without active vacuum and with external dry ice cooling. The reaction mixture was allowed to warm over about $10 \mathrm{~min}$ to approach completion of ligand metathesis. Excess 4a was removed by evacuation at room temperature for $30 \mathrm{~min}$. Complexes $\mathbf{5 b}, \mathbf{5 c}$, and $\mathbf{5 d}$ were all prepared similarly, except with two cycles of exposure of $\mathbf{2}$ to the respective phenols.

The Kelvin Probe. The work function of the surface was studied using a Kelvin probe that was located in a nitrogen atmosphere glovebox and driven using homemade circuitry. The sinusoidally oscillating reference electrode was driven by a piezoelectric ceramic made of lead zirconate titanate (APC International Ltd; Model APC 850). The tubular piezoelectric (outside diameter, 0.375 in.; inside diameter, 0.281 in.; length, 0.789 in.) was electrically shielded and held vertically. The piezo was driven using a Hewlett-Packard 200AB audio oscillator, and its frequency was measured using a Hewlett-Packard 5334B universal counter. The surface potential difference signal was amplified using a Perkin-Elmer 5182 preamplifier and was filtered using an EG\&G 5206 two-phase lock-in analyzer. To find the probe resonant frequency, the probe was brought close to the surface of a gold standard, and a 30-V direct current (dc) potential was applied to its tip. Alternating current voltage was then applied to the piezo and was scanned in the range $100-300 \mathrm{~Hz}$. When the resonant frequency of the probe $(\approx 210$ $\mathrm{Hz}$ ) was reached, a maximum reading of the potential difference between the probe tip and the gold was shown using the lockin analyzer. A sample was then brought close to the probe, and a $30-\mathrm{V}$ dc potential was applied to the probe tip. When the probe was set at the same distance from the sample as was used for the $\mathrm{Au}$, a controlled, opposite-bias dc voltage, which was monitored by a multimeter, was applied to the probe. This voltage was adjusted until the reading on the lock-in analyzer was null. The work function difference between the sample and the $\mathrm{Au}$ could then be determined from the magnitude of this bias potential.

Determining the Work Function of Modified and Unmodified ITO. An ITO sample (ca. $1 \mathrm{~cm}^{2}$ ) was prepared and was exposed to vapor of $\mathbf{1}$ as described above. Excess $\mathbf{1}$ was removed by evacuation, and the treated ITO was transferred into a nitrogen atmosphere glovebox containing the Kelvin probe The work functions of untreated ITO and ITO coated with 2, $\mathbf{5 a}, \mathbf{5 b}, \mathbf{5 c}$, and $\mathbf{5 d}$ were then measured using the method outlined above.

Quartz Crystal Microgravimetry. Quartz crystals (10 000 $\mathrm{MHz}$, AT-cut) equipped with $1000 \AA$ ITO on 500- $\AA$ Al electrodes were obtained from International Crystal Manufacturing and were used as received. The QCM was driven using an ICM 35360 commercial crystal oscillator. The crystal frequency was measured using a Hewlett-Packard 53131A universal counter and was recorded using a laboratory computer.

Preparation and Testing of Hole-Only Devices. ITO slides were cut into coupons approximately $20 \mathrm{~mm} \times 20 \mathrm{~mm}$. A 10 $\mathrm{mm} \times 20 \mathrm{~mm}$ strip of ITO was defined by covering the central area of the coupon with tape and etching away the exposed ITO using concentrated $\mathrm{HCl}$. The tape was removed, and the remaining ITO was polished using an aqueous suspension of silica gel (grade 60, 230-400 mesh, Aldrich) for $30 \mathrm{~s}$, then rinsed with $0.1 \mathrm{M} \mathrm{KOH}$ and then hot water. The polished coupons were then rubbed with a sponge soaked in $2 \%$ aq Tergitol (Aldrich) for $30 \mathrm{~s}$ and were then rinsed with distilled water. The coupons were then sonicated in the Tergitol detergent solution for $25 \mathrm{~min}$, then rinsed with distilled water, and then sonicated again, successively, in boiling acetone, isopropyl alcohol, and methylene chloride (5 min for each solvent, 3 ). The coupons were then dried overnight under $\mathrm{N}_{2}$ at $110{ }^{\circ} \mathrm{C}$. Surface complexes $\mathbf{5 b}, \mathbf{5} \mathbf{c}$, and $\mathbf{5} \mathbf{d}$ were then prepared on these electrode surfaces as described above. Deposition of $N, N^{\prime}$-bis(1-naphthyl)- $N, N^{\prime}$-diphenyl-1,1-biphenyl-4,4'-diamine (99.9\%, Aldrich, $\alpha$-NPD) and aluminum (Alfa Aesar) layers was performed using an Edwards 306A thermal evaporation system at a base pressure of $8 \times 10^{-7}$ mbar. $\alpha-N P D$ was used as received and was deposited at a rate of $2-3 \AA / \mathrm{s}$ to a thickness of approximately $1400 \AA$. Aluminum contacts were defined by a shadow mask and were deposited at a rate of $12 \AA /$ s to a total thickness of $600 \AA$. The overlap of the ITO stripe and Al contacts defined the active device areas $\left(4 \mathrm{~mm}^{2}\right.$ and $\left.8 \mathrm{~mm}^{2}\right)$. Device testing was accomplished using a Keithley 2400 Sourcemeter controlled by Labview software. Devices were cycled from 0 to $7 \mathrm{~V}$. A device using a cleaned ITO electrode was used as the control.

\section{Results and Discussion}

ITO/glass slides were cleaned and placed in a reaction chamber that could be evacuated to about $10^{-3}$ Torr and that was equipped with stopcocks to admit vapor of $\mathbf{1}$ or phenols, as previously described. ${ }^{17}$ Surface alkoxytin complexes metathesize readily with phenols because of their $\mathrm{p} K_{\mathrm{a}}$ values ${ }^{19}$ relative to the tert-butyl alcohol product (ca. 10 and 18, respectively). According to the volatility of the phenols, slightly different deposition conditions were used to ensure completeness of the metathesis reaction. In general, when ITO was exposed to $\mathbf{1}$ the reaction vessel fogged near the site of external cooling; this disappeared and the surface became transparent again on subsequent evacuation. All surface-treated ITO materials (Scheme 1) were colorless. IR analysis showed the presence of these surface complexes; clean ITO was used as the background.

The work function $(\phi)$ of a freshly prepared sample of untreated ITO was measured as a baseline with an accuracy of $\pm 0.2 \mathrm{eV}$. Work-function measurements of tin alkoxide complexmodified ITO (2) were then made, and samples were transferred in a closed reaction chamber out of the nitrogen-filled glovebox. Complexes $\mathbf{5 a}, \mathbf{5 b}, \mathbf{5 c}$, and $\mathbf{5 d}$ were prepared on individual pieces of 2-modified ITO as described above. The reaction chamber was then transferred back into the glovebox, and the work function of the ITO modified with $\mathbf{5}$ was measured using the same gold and untreated ITO standards.

Both the loadings and the stoichiometries of the surface tin complexes on ITO were determined using the QCM technique; ${ }^{20,21} \mathbf{4 b}, \mathbf{4 c}$, and $\mathbf{4 d}$ were used in these QCM studies because their relatively large molecular weights enabled the most accurate measurements of frequency changes. An evacuable reaction chamber equipped with two separate inlet ports was used. The QCM ensemble was attached to this apparatus (Figure 1), which allowed for exposure of both ITO-coated Al electrodes to the vapor of choice. Tin alkoxide $\mathbf{1}$ (ca. $300 \mathrm{mg}$ ) was placed in a small vial attached to one port by a high-vacuum stopcock, and a phenol (ca. $300 \mathrm{mg}$ ) was placed in a second small vial attached to the other inlet port via a high-vacuum stopcock. Both were degassed by three freeze-pump-thaw cycles. The assembly was isolated from the two organic reagents and was evacuated for $2 \mathrm{~h}$ at $3 \times 10^{-3}$ Torr. With the vessel opened to the vacuum system, the QCM was exposed to 1 by opening the appropriate stopcock. Rapid adsorption of $\mathbf{1}$ was noted gravimetrically. An initial frequency change of ca. $50 \mathrm{~Hz}$ was recorded (over about $3 \mathrm{~min}$ ), but rapid desorption of excess 1 was also measured by the QCM when the vessel was evacuated at $3 \times 10^{-3}$ Torr for approximately $10 \mathrm{~min}$. A net frequency 
SCHEME 1: Synthesis of Surface Tin Phenoxides ${ }^{a}$

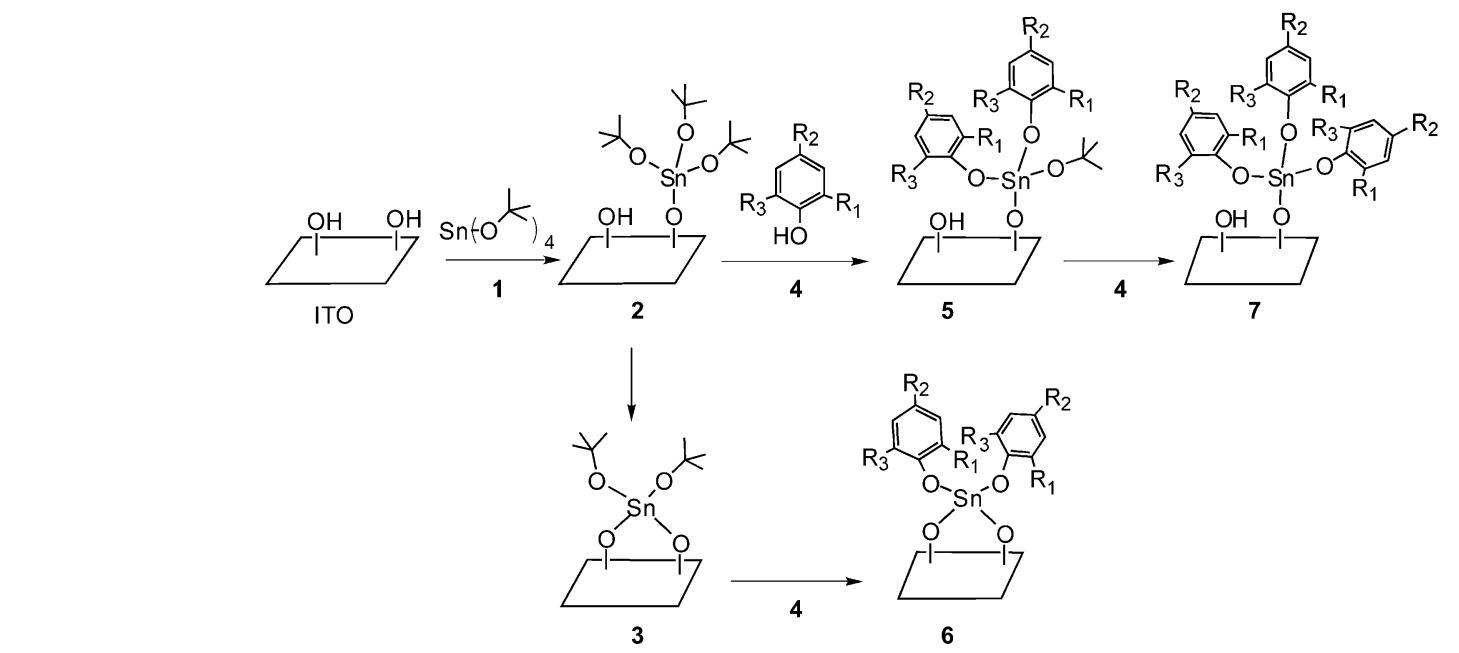

${ }^{a}$ a: $\mathrm{R}_{1}=\mathrm{R}_{3}=\mathrm{R}_{2}=\mathrm{H} ; \mathbf{b}: \mathrm{R}_{1}=\mathrm{R}_{3}=\mathrm{H}, \mathrm{R}_{2}=\mathrm{F} ; \mathbf{c}: \mathrm{R}_{1}=\mathrm{R}_{3}=\mathrm{H}, \mathrm{R}_{2}=\mathrm{CF}_{3} ; \mathbf{d}: \mathrm{R}_{1}=\mathrm{R}_{3}=\mathrm{F}, \mathrm{R}_{2}=\mathrm{H}$.

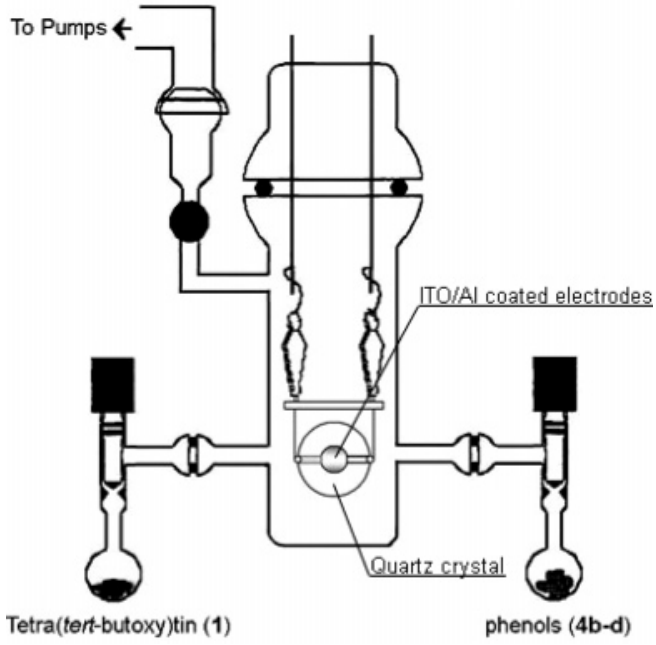

Figure 1. Diagram of the cell used for QCM measurements.

change of $44 \mathrm{~Hz}$ was observed (Figure 2). If deposition occurred with protolytic loss of one alkoxy group (Scheme 1) (as was found to predominate in $\mathrm{UHV}^{17}$ and consistent with a lowsurface hydroxyl group content of ca. 1 per $100 \AA^{222}$ ), this reaction would yield a net molecular weight increase of $337 \mathrm{D}$. The measured frequency change would thus correspond to a nominal coverage (surface loading, "£”) of the ITO by 2 of $0.181 \pm 0.004 \mathrm{nmoles} / \mathrm{cm}^{2}$ (correcting for a surface roughness factor of $\left.1.6^{23}\right)$. The stopcock to the bulb containing the $\mathbf{4 b}$ was opened for $3 \mathrm{~min}$. Excess phenol was then removed in vacuo. A net frequency change of $20 \mathrm{~Hz}$ was observed (Figure 2). If this reaction proceeded with replacement of two alkoxy groups (as in $\mathrm{UHV}^{17}$ ), there would be a net molecular weight increase of $76 \mathrm{D}$ per complex (Scheme 1). The measured frequency change would correspond to a surface loading for $\mathbf{5}$ of 0.18 $\mathrm{nmol} / \mathrm{cm}^{2}$, in good agreement with the loading measured for 2 . Other stoichiometries for deposition and metathesis (Scheme

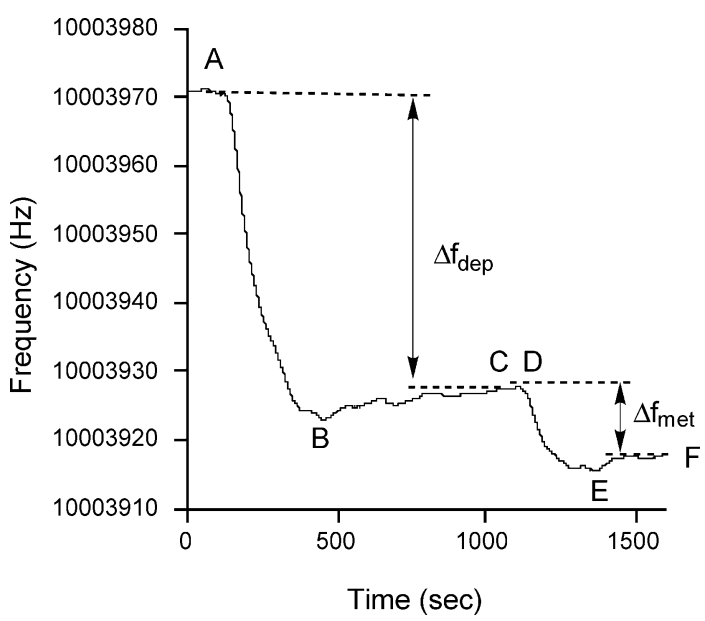

Figure 2. QCM measured changes in frequency on reaction first between ITO and 1 and then between 2 and $\mathbf{4 b}$. Points (A) begin exposure to 2 ; (B) end exposure to 2 and begin evacuation; (C) end evacuation; (D) begin exposure to 4; (E) end exposure to 4 and begin evacuation; (F) end evacuation. $\Delta f_{\text {dep }}$ is the measured frequency change on formation of $\mathbf{2}$, and $\Delta f_{\text {met }}$ is the measured frequency change for ligand metathesis to give $\mathbf{5}$.

1) were also evaluated using these data, but the correspondence between surface loadings for alkoxide precursors and phenoxide products was poorer in these other cases (Table 1). Similar observations were made using $\mathbf{4} \mathbf{c}$ and $\mathbf{4 d}$ (Figure 2). In other words, $\mathbf{2}$ is the major component of surface alkoxide formed on ITO under typical laboratory conditions, and $\mathbf{5}$ is the major product of ligand metathesis.

An important ramification of the studies described herein, which comprise both work-function changes $(\Delta \phi)$ for a series of phenoxide complexes (5) relative to ITO $\left(\Delta \phi=\phi_{5}-\phi_{\text {ITO }}\right)$ and surface complex loading measurements for $\mathbf{5}$, is that surface complex molecular dipole moment normal components $\left(\mu_{z(\mathbf{5})}\right)$ and total surface dipole could now be determined if dielectric

TABLE 1: Net Frequency Changes $(\Delta f, \mathrm{~Hz})$ and Corresponding Calculated Surface Loadings $\left(£, \mathrm{nmol} / \mathrm{cm}^{2}\right)$ for $\mathrm{Alkoxide}$ Precursors and Phenoxide Products, According to the Reaction Stoichiometries Shown in Scheme $1^{a}$

\begin{tabular}{ccccccc}
\hline$\Delta f_{\text {dep }}$ & $\Delta f_{\text {met }}$ & $£(\mathbf{2})^{b}$ & $£(3)$ & $£(\mathbf{2} \rightarrow \mathbf{5})^{b}$ & $£(\mathbf{3} \rightarrow \mathbf{6})$ & $£(\mathbf{2} \rightarrow \mathbf{7})$ \\
\hline $44.0 \pm 1.0$ & $10.0 \pm 1.0$ & $0.181 \pm 0.004$ & $0.232 \pm 0.005$ & $\mathbf{5 b}: 0.182 \pm 0.018$ & $\mathbf{6 b}: 0.182 \pm 0.018$ & $\mathbf{7 b}: 0.121 \pm 0.012$ \\
$47.0 \pm 1.0$ & $20.0 \pm 1.0$ & $0.193 \pm 0.004$ & $0.247 \pm 0.005$ & $\mathbf{5 c :} 0.157 \pm 0.008$ & $\mathbf{6 c :}: 0.157 \pm 0.008$ & $\mathbf{7 c}: 0.105 \pm 0.005$ \\
$42.0 \pm 1.0$ & $15.0 \pm 1.0$ & $0.172 \pm 0.004$ & $0.221 \pm 0.005$ & $\mathbf{5 d}: 0.185 \pm 0.012$ & $\mathbf{6 d :} 0.185 \pm 0.012$ & $\mathbf{7 d}: 0.123 \pm 0.008$
\end{tabular}

${ }^{a}$ Note that the most consistent measurements for alkoxide $\rightarrow$ phenoxide loadings are for $\mathbf{2} \rightarrow \mathbf{5}$. ${ }^{b}$ Best fit for surface complex loading $\left(\mathrm{nmole} / \mathrm{cm}^{2}\right)$. 
TABLE 2: Gas-Phase Dipole Moments for Parent Phenols (4), $\Delta \phi$ for Surface Phenoxide Complexes (5), Calculated Complex Dipole Moments for 5 normal to the ITO Surface $\left(\mu_{z(5)}\right)$, and Dipole Moments normal to the ITO Surface $\times$ Surface Complex Loading $\left(\mu_{z(5)} \times f_{5}\right)$

\begin{tabular}{lcrlll}
\hline \multicolumn{1}{c}{ parent phenol } & $\Delta \phi(\mathrm{eV})^{a}$ & \multicolumn{1}{c}{$\begin{array}{c}\mu_{z(\text { (phenol) }} \\
(\mathrm{D})^{b}\end{array}$} & $\begin{array}{l}\mu_{z(\mathbf{5})} \\
(\mathrm{D})^{c}\end{array}$ & $\mu_{\mathrm{z}(\mathbf{5})} \times \mathfrak{f}_{(\mathbf{5})}{ }^{d}$ \\
\hline phenol (4a) & 0.59 & -0.44 & $\mathrm{e}$ & $e$ \\
p-fluorophenol (4b) & 1.10 & 1.20 & 1.67 & 0.301 \\
4-(trifluoromethyl)phenol (4c) & 1.48 & 3.06 & 2.60 & 0.416 \\
2,6-difluorophenol (4d) & 0.47 & -1.85 & 0.66 & 0.132
\end{tabular}

${ }^{a} \phi$ for 5 relative to ITO. ${ }^{b}$ Positive values indicate the negative end of the dipole is oriented away from the phenolic oxygen. ${ }^{c}$ Positive values indicate the negative end of the dipole is oriented away from the ITO surface. ${ }^{d}$ Relative values. ${ }^{e}$ Surface loading not measured by QCM.
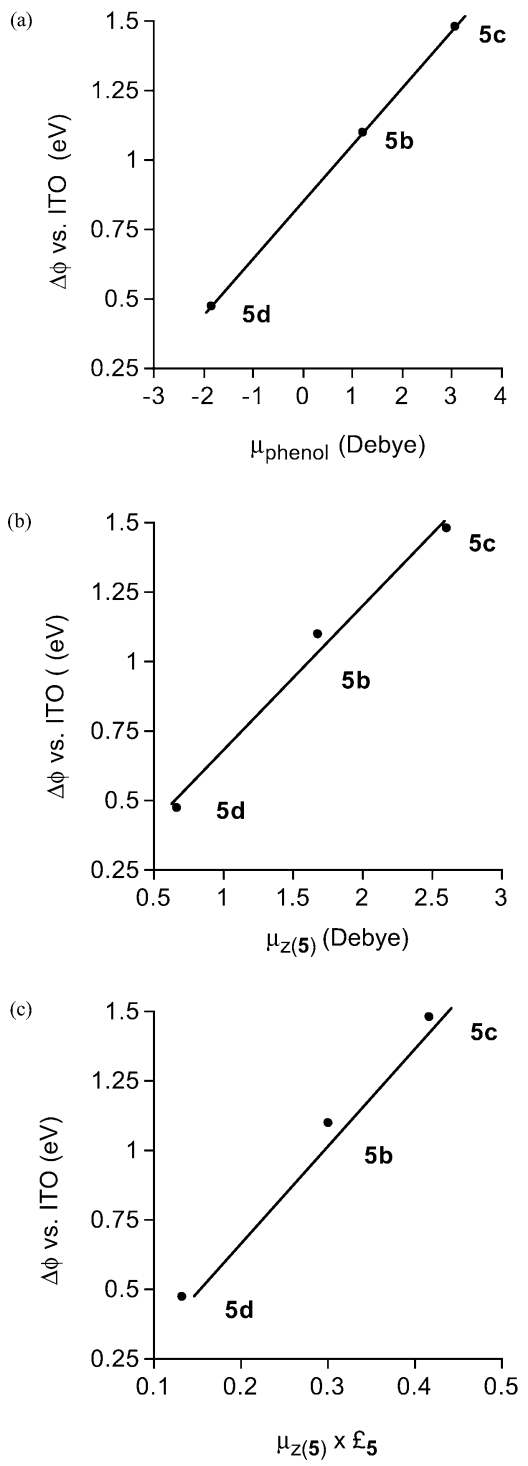

Figure 3. A good correlation exists between measured $\Delta \phi$ (vs ITO) and (a) the dipole moment of the parent phenols, $\mu_{\text {phenol; }}$ (b) the calculated complex dipole moment, $\mu_{z(\mathbf{5})}$; and (c) the total dipole $(z$

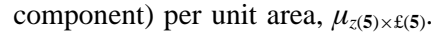

constants for the surface complex monolayers, as opposed to values for the bulk materials, were known; were the Helmholtz model applicable, the total surface dipole should correlate with $\Delta \phi$. Even in the absence of these monolayer dielectric constants, it is possible to calculate relative complex dipole moment normal component values $\left(\mu_{z(\mathbf{5})}\right)$; for $\mathbf{5 b}, \mathbf{5} \mathbf{c}$, and $\mathbf{5 d}, \mu_{z(\mathbf{5})}=1.67,2.60$,
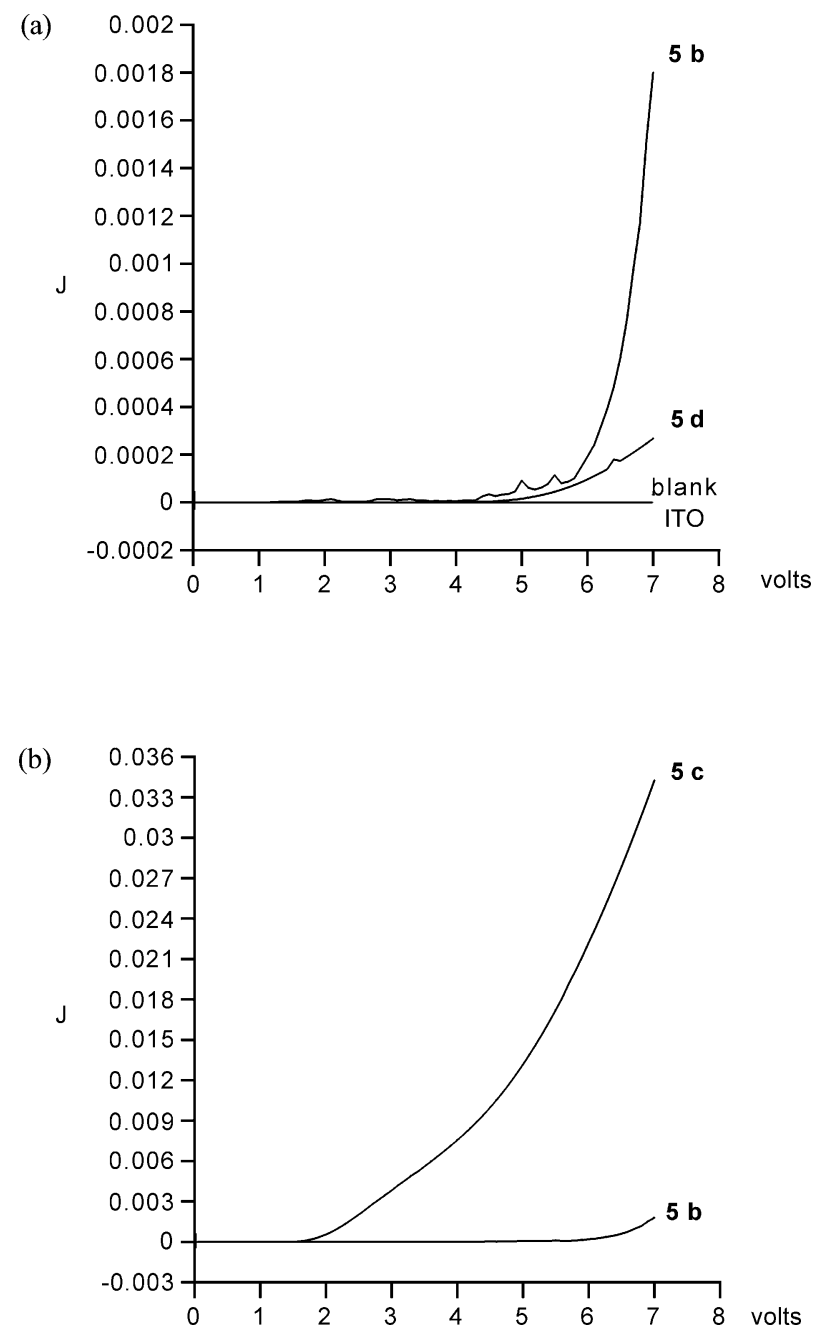

Figure 4. Current density $\left(J, \mathrm{~A} / \mathrm{cm}^{2}\right)$ vs voltage curves $(0-7 \mathrm{~V})$ for simple hole-only diodes prepared using each of three surface tin complexes compared with ITO. (a) Complexes $\mathbf{5 b}$ and $\mathbf{5 d}$ vs ITO; (b) complex 5c vs $\mathbf{5 d}$.

and $0.66 \mathrm{D}$, respectively (Table 2). It is noteworthy that a good correlation does exist between $\Delta \phi$ and $\mu_{z(\mathbf{5})}$ and, even more significantly, with the total dipole ( $z$ component) per unit area, $\mu_{z(\mathbf{5}) \times\{5}$, as predicted by the Helmholtz equation (Figure 3 ).

Current density-voltage $(J-V$, Figure 4$)$ characteristics were determined for simple hole-only diodes fabricated with ITO anodes surface-modified with $\mathbf{5 b}, \mathbf{5 c}$, and $\mathbf{5 d}$. All three surfacemodified electrode diodes showed higher current densities than the control, which used clean ITO as the anode. These diodes had increases in current density at $7 \mathrm{~V}$ that were 133 (5b), 2500 $(\mathbf{5 c})$, and 18 (5d) times greater than those measured for the clean ITO electrode control device. Examination of idealized structures for tetrahedrally substituted surface tin complexes $\mathbf{5}$ shows that rotation about the $\mathrm{Sn}-\mathrm{O}-\mathrm{C}$ linkage can generate a family of rotamers. Each member of this family contributes to $\mu_{z(\mathbf{5})}$ according to its particular conformation; we assume that, on average, complex geometries for $\mathbf{5} \mathbf{b}-\mathbf{d}$ are similar. Thus the net surface dipole that results from tin complex formation apparently involves the superposition of the dipole introduced by replacement of a surface $\mathrm{OH}$ by a surface tin species, plus any net dipole moment of the various $\mathrm{Sn}-\mathrm{O}$ interactions, both with regard to the surface and through bonding to the various alkoxides, and the dipole moments of the phenoxide ligands themselves. The relationship between measured device current densities and $\mu_{z(\mathbf{5}) \times £ 5}$ at $7 \mathrm{~V}$ remains to be interpreted from a 
theory perspective, and future device work will be directed toward elucidation of this important issue.

\section{Conclusions}

We have demonstrated that controlled surface modification of ITO can be effected chemically by a straightforward procedure of surface complex deposition and ligand exchange, and we have shown that such surface modification has a direct, systematic, and quantitative impact on the behavior of simple devices incorporating these surface modifications. Furthermore, the conformity of the effects of surface dipole magnitude and density on device behavior that we have demonstrated lends direct support for the Helmholtz model to predict simple device outcomes based on molecular processes for surface modification, even when such dipoles might be dilutely and nonuniformly distributed across the electrode surface.

Acknowledgment. The authors acknowledge Prof. Robert A. Pascal for calculation of the gas-phase phenol dipole moment and phenol acidity data, Professor Antoine Kahn and Mr. Calvin $\mathrm{K}$. Chan for advice in the design and construction of the Kelvin probe, and Prof. Zoltán Soos for helpful discussions. They also thank the National Science Foundation for financial support.

Supporting Information Available: IR spectra of surfacemodified ITO/glass: (a) [ITO]-[O]- $\mathrm{Sn}\left(\mathrm{OBu}^{t}\right)\left(\mathrm{OC}_{6} \mathrm{H}_{5}\right)_{2}(\mathbf{5 a})$, (b) $[\mathrm{ITO}]-[\mathrm{O}]-\mathrm{Sn}\left(\mathrm{OBu}^{t}\right)\left(\mathrm{OC}_{6} \mathrm{H}_{4} \mathrm{~F}\right)_{2}(\mathbf{5 b})$, (c) $[\mathrm{ITO}]-[\mathrm{O}]-\mathrm{Sn}-$ $\left(\mathrm{OBu}^{t}\right)\left(\mathrm{OC}_{6} \mathrm{H}_{4} \mathrm{CF}_{3}\right)_{2}(\mathbf{5 c})$, (d) [ITO]-[O]- $\mathrm{Sn}\left(\mathrm{OBu}^{t}\right)\left(\mathrm{OC}_{6} \mathrm{H}_{3} \mathrm{~F}_{2}\right)_{2}$ (5d); QCM measured changes in frequency on reaction first between ITO and $\mathbf{1}$ and then between $\mathbf{2}$ and $\mathbf{4 c}$ and $\mathbf{4 d}$. These materials are available free of charge via the Internet at http://pubs.acs.org.

\section{References and Notes}

(1) Nüesch, F.; Forsythe, E. W.; Le, Q. T.; Gao, Y.; Rothberg, L. J. J. Appl. Phys. 2000, 87, 7973 . 87,295

(2) Sugiyama, K.; Ishii, H.; Ouchi, Y.; Seki, K. J. Appl. Phys. 2000,

(3) Steuber, F.; Staudigel, J.; Stössel, M.; Simmerer, J.; Winnacker, A. Appl. Phys. Lett. 1999, 74, 3558

(4) Wu, C. C.; Wu, C. I.; Sturm, J. C.; Kahn, A. Appl. Phys. Lett. 1997, 70, 1348

(5) Choi, M. W.; Cho, K.; Sung, C.; Yang, J.; Noh, Y. Y. M.; Choi, J. C.; Jeong, K. J. Vac. Sci. Technol. B 2004, 22, 758.

(6) Tang, J. X.; Li, Y. Q.; Zheng, L. R.; Hung, L. S. J. Appl. Phys. 2004, 95, 4397.

(7) Ke, L.; Kumar, R. S.; Zhang, K.; Chua, S. J.; Wee, A. T. S. Synth. Met. 2004, 140, 295.

(8) Christmann, K. Introduction to Surface Physical Chemistry; Springer-Verlag: New York, 1991. 605.

(9) Ishii, H.; Sugiyama, K.; Ito, E.; Seki, K. Adv. Mater. 1999, 11,

(10) Ito, E.; Oji, H.; Furuta, M.; Ishii, H.; Oichi, K.; Ouchi, Y.; Seki, K. Synth. Met. 1999, 101, 654.

(11) Milliron, D. J.; Hill, I. G.; Shen, C.; Kahn, A.; Schwartz, J. J. Appl. Phys. 2000, 87, 572 .

(12) Zehner, R. W.; Parsons, B. F.; Hsung, R. P.; Sita, L. R. Langmuir 1999, 15, 1121.

(13) Appleyard, S. F. J.; Day, S. R.; Pickford, R. D.; Willis, M. R. J. Mater. Chem. 2000, 10, 169.

(14) Gardner, T. J.; Frisbie, C. D.; Wrighton, M. S. J. Am. Chem. Soc. 1995, 117, 6927.

(15) Nüesch, F.; Rotzinger, F.; Si-Ahmed, L.; Zuppiroli, L. Chem. Phys. Lett. 1998, 288, 861.

(16) Malinsky, J. E.; Jabbour, G. E.; Shaheen, S. E.; Anderson, J. D.; Richter, A. G.; Marks, T. J.; Armstrong, N. R.; Kippelen, B.; Dutta, P.; Peyghambarian, N. Adv. Mater. 1999, 11, 227.

(17) Span, A. R.; Bruner, E. L.; Bernasek, S. L.; Schwartz, J. Langmuir 2001, 17, 948 .

(18) Bruner, E. L.; Koch, N.; Span, A. R.; Bernasek, S. L.; Kahn, A.; Schwartz, J. J. Am. Chem. Soc. 2002, 124, 3192.

(19) Carey, F. A. Organic Chemistry, 4th ed.; McGraw-Hill Higher Education: Boston, 2000.

(20) Sauerbrey, G. Z. Phys. 1959, 155, 206.

(21) Aronoff, Y. G.; Chen, B.; Lu, G.; Seto, C.; Schwartz, J.; Bernasek, S. L. J. Am. Chem. Soc. 1997, 115, 2259.

(22) VanderKam, S. K.; Gawalt, E. S.; Schwartz, J.; Bocarsly, A. B. Langmuir 1999, 15, 6598.

(23) Carolus, M. D.; Guo, J.; Schwartz, J. Unpublished results. 